\title{
Studies of lignin as reinforcement for plastics composites
}

\section{O.A.T. Dias, D.R. Negrão, R.C. Silva, C.S. Funari, I. Cesarino \& A.L. Leao}

To cite this article: O.A.T. Dias, D.R. Negrão, R.C. Silva, C.S. Funari, I. Cesarino \& A.L. Leao (2016) Studies of lignin as reinforcement for plastics composites, Molecular Crystals and Liquid Crystals, 628:1, 72-78, DOI: 10.1080/15421406.2015.1137677

To link to this article: https://doi.org/10.1080/15421406.2015.1137677

曲 Published online: 13 May 2016.

Submit your article to this journal $\pi$

Џll Article views: 255

View Crossmark data ¿

7 Citing articles: 7 View citing articles $\square$ 


\title{
Studies of lignin as reinforcement for plastics composites
}

\author{
O.A.T. Dias ${ }^{a}$, D.R. Negrão ${ }^{b}$, R.C. Silva ${ }^{a}$, C.S. Funari ${ }^{a}$, I. Cesarino ${ }^{a}$, and A.L. Leao ${ }^{a}$ \\ ${ }^{\mathrm{a}}$ São Paulo State University (UNESP), College of Agricultural Sciences (UNESP/FCA), Botucatu, SP, Brazil; ${ }^{\mathrm{b} C e n t r e}$ \\ of Nuclear Energy in the Agriculture, (CENA/USP), Piracicaba, SP, Brazil
}

\begin{abstract}
The growing environmental concerns and depletion of fossil fuels resulted in an increased interest in environmentally friendly materials based on natural polymers. Efforts are being made to introduce the lignin in plastic composites such as polypropylene, with the aim of producing bio-based materials with desirable mechanical characteristics. In this study, blends of lignin powder and polypropylene were extruded and testing samples were produced by injection molding process. The produced materials were tested for physical, mechanical and thermal properties. The results showed that the incorporation of the lignin powder in polypropylene matrix resulted in a composite with suitable property application for various industrial fields, especially those were mechanical features are crucial, such as the replacement of engineering plastics.
\end{abstract}

\section{KEYWORDS}

lignin-based composite; polypropylene; natural polymer; kraft process; lignocellulosic; biocomposites

\section{Introduction}

The growing environmental concerns on depletion of fossil fuels resulted in an increased interest on environmental friendly materials based on natural polymers [1]. There are many approaches to adopt environmental friendly solutions. Among them it is the loading polyolefins with as much of biopolymer as possible. However, a blend of a polyolefin with a biopolymer would not be compatible due to the inherent differences in their physical and chemical properties. The major source of biopolymers can be obtained from lignocellulosic materials, especially that from waste materials, which are an underutilized natural resources. Lignin is the second most abundant biopolymer component in the ligninocellulosic material, which has a complex and non-uniform structure with aliphatic and aromatic constituents [2]. Lignin gives rigidity to the cellular walls and thus contributes to the mechanical strength of the timber [3]. Because of an amorphous heterogeneity behavior, lignin also has a thermoplastic characteristic [4].

Actually, about 1 a $2 \%$ of isolated lignin is used to create a wide range of special products [5], the remaining fraction is burned to generate energy and recover chemical in the paper pulp industries. After lignin fragmentation, various chemicals products can be used such as dispersants, surfactants, activated carbon, methanol and carbon fiber, which can transform this biopolymer into a valuable raw material [6]. Also, lignin can be used in various applications, such as adhesives, asphalts, polyurethanes, and phenol-formaldehyde resin formulations [7, $8]$. 
In terms of industrial chemical modification of lignin, Kraft pulping process is the dominant global technology [9]. During the conventional Kraft cooking, hydroxide and hydrosulfide anions react with lignin, causing fragmentation of the polymer into smaller water/alkalisoluble fragments [10]. This fragmentation proceeds through the cleavage of the linkages holding the phenylpropane units together, with a concomitant generation of free phenolic hydroxyl groups. The presence of these hydroxyl groups increases the hydrophilic of lignin as well as its fragments. Thus, the solubility of the lignin in the cooking liquor is increased, and the carbon-carbon linkages, are more stable, tending to survive the pulping process [11].

Due to lignin structure, its potential for material applications has been investigated as compatibilizer as well as for its antioxidant [12] and antimicrobial properties [13]. Lignin has interesting grafting and crosslinking abilities that makes it an interesting material for its use in polyurethanes and other polymeric systems [8]. Lignin-polymer blends and composites have been reviewed recently, such as development of modified lignin based on eco-friendly products and studies on utilization of lignins to develop value added biocomposites $[14,15]$. Lignin can be used as filler in a variety of resins such as polypropylene (PP), polystyrene, polyurethanes, etc. However, lignin and PP, for example, are not compatible. Lignin has polar characteristic and together to its three-dimensional structure and the inertness of PP make those interactions very difficult, resulting on phase-separation during processing and poor mechanical properties of the composites. One way to improve the interactions between lignin and PP is through the use of compatibilizers, as epoxy, modified poly (styrene-co-ethylene-cobutylene-co-styrene), ethylene-vinyl acetate and polyethylene grafted with maleic anhydride $[16,17]$.

The objective of this work was to develop new lignin-based polypropylene composites with mechanical properties similar to the virgin polypropylene. The composites and polypropylene were characterized by thermal analysis and mechanical properties.

\section{Materials and method}

\subsection{Materials}

In the production process of the composite was used virgin polypropylene (PP) from Braskem SA, Brazil, with melt flow index (MFI) of $3.5 \mathrm{~g} / 10 \mathrm{~min}\left(230^{\circ} \mathrm{C} / 2.16 \mathrm{~kg}\right)$, lignin powder acidrecovered from hardwood Kraft pulp was kindly provided by the company Lwarcel (Lençóis Paulista, São Paulo, Brazil) and PP grafted with maleic anhydride (PP-g-MA) under the trade name Epolene (Eastman Chemical Epolene E43) was used as compatibilizer agent.

\subsection{Lignin precipitation}

Lignin was acid-recovered [18] from black liquor generated by Kraft pulping process which utilizes hardwood. Lignin was acid-recovered by adding $3 \mathrm{M} \mathrm{H}_{2} \mathrm{SO}_{4}$ in the black liquor, which was to heating at $60^{\circ} \mathrm{C}$ and then acidified till reaching $\mathrm{pH}$ 3.0. Then, the supernatant was discarded and lignin was dried overnight at $60^{\circ} \mathrm{C}$ until reaching constant weight. Moisture of lignin ranged between 4 and 5\%.

\subsection{Composites production}

In order to evaluate the importance of lignin composites, different lignin fractions were used in the composite besides the use of the compatibilizing agent. Also, it was assessed whether 
the coupling agent caused changes in the mechanical properties of the composite and whether lignin acts as a reinforcing or filler agent. Lignin was blended with PP and the compatibilizing agent. The processing temperature in the extruder was $160^{\circ} \mathrm{C}$ in order to prevent $\mathrm{PP}$ degradation and providing the fusion between the materials. The material was processed in twin screw extruder Werner \& Pfleiderer Krupp model ZSK-25, and chopped a SAGEC Model GS mill 70. The next step was to inject PP and lignin as the specimen in injection Semerano Model $650 / 247$.

\subsection{Statistical analysis}

Impact, flexural and tensile tests were performed to evaluate the mechanical characteristics of the composite. Studies of the response to the mechanical test were performed considering the technique of analysis of variance for the model with a factor complemented by the Scott-Knott multiple comparisons test, at 5\% probability, by using Sisvar software.

\subsection{Mechanical test}

Tensile and flexural properties of the composites were measured by Emic (Model DL10000), testing machine, according to standards ASTM D 638 and ASTM D 790 respectively. The notched Izod impact strength was measured with an Olsen Tilsen Impact tester (model No. 43-02-01) according to ASTM D 256 using a pendulum of $5 \mathrm{ft}-\mathrm{lb}$.

\subsection{Thermogravimetric analysis (TG)}

The tests were performed using a TG-DTA Simultaneous equipment, Model SDT 2960, TA Instruments, at a heating rate of $10^{\circ} \mathrm{C} / \mathrm{min}$ and temperature range of 25 to $800^{\circ} \mathrm{C}$ in nitrogen atmosphere.

\subsection{Differential scanning calorimetry (DSC)}

Differential scanning calorimetry (DSC) analyses of the composites were conducted with a DSC Q10 (TA instrument). The sample was scanned between 25 and $250^{\circ} \mathrm{C}$ at a heating rate of $10^{\circ} \mathrm{C} / \mathrm{min}$. The degree of crystallinity was calculated dividing enthalpy of fusion of material studied by enthalpy of fusion of $100 \%$ crystalline PP (207 J/g) [19, 21].

\section{Results}

\subsection{Mechanical properties}

\subsubsection{Impact strength}

The impact resistance measurements evaluate the ability of a material to resist breakage under application of force at high speed. In the present study, there were slight fluctuations in impact resistance of materials (Table 1), but there is no significant difference between the treatments. However, the introduction of compatibilizing agents improved impact resistance resulting in a resistance similar to that of the virgin PP. Toriz et al. [22] attributed the improvement to the possible formation of ester linkages between lignin and coupling agent. According Sailaja et al. [20], an increase in lignin fraction of Low density polyethylene (LDPE) composites caused a 
Table 1. Tensile, Flexural, and Impact Properties of Composites prepared with Kraft lignin, polypropylene (PP) and maleic anhydride (PP-g-MA).

\begin{tabular}{lccccc}
\hline (PP/lignin)/PP-g-MA & $\begin{array}{c}\text { Impact Strength } \\
(\mathrm{J} / \mathrm{m})\end{array}$ & $\begin{array}{c}\text { Flexural Strength } \\
(\mathrm{MPa})\end{array}$ & $\begin{array}{c}\text { Tensile Strength } \\
(\mathrm{MPa})\end{array}$ & $\begin{array}{c}\text { Flexural Modulus } \\
(\mathrm{GPa})\end{array}$ & $\begin{array}{c}\text { Tensile Modulus } \\
(\mathrm{GPa})\end{array}$ \\
\hline$(100 / 0) / 0$ & $16.84 \mathrm{a}$ & $36.19 \mathrm{a}$ & $24.87 \mathrm{a}$ & $1.109 \mathrm{a}$ & $1.240 \mathrm{a}$ \\
$(90 / 10) / 0$ & $14.97 \mathrm{a}$ & $30.57 \mathrm{~b}$ & $18.05 \mathrm{~b}$ & $1.181 \mathrm{a}$ & $0.823 \mathrm{~b}$ \\
$(90 / 10) / 3$ & $16.77 \mathrm{a}$ & $32.04 \mathrm{~b}$ & $18.38 \mathrm{~b}$ & $1.059 \mathrm{a}$ & $1.060 \mathrm{a}$ \\
$(70 / 30) / 3$ & $16.56 \mathrm{a}$ & $40.37 \mathrm{c}$ & $17.62 \mathrm{~b}$ & $1.072 \mathrm{a}$ & $1.135 \mathrm{a}$ \\
$\mathrm{CV}(\%)$ & 11.15 & 9.10 & 4.57 & 16.07 & 11.55 \\
\hline
\end{tabular}

Means followed by the same letter within a column are not significantly different by Scott-Knot method $(P>0.05)$.

decrease in impact resistance of the material. The same behavior was observed by Sahoo et al. [21], which used polybutylene succinate (PBS) and lignin blends.

\subsubsection{Tensile properties}

The tensile test measure the maximum stress that a material can resist while being stretched or pulled before failing or breaking. The tensile modulus and tensile strength at break of the different materials are shown in Table 1. The tensile strength decreased with the addition of lignin, this was expected since the poor adhesion between the components of the system increases the chances of failure. Furthermore, it can be seen that the coupling agent had little effect on tensile strength (Table 1). Similarly, according to Sahoo et al. [21] incorporation of lignin to PP gradually decreased the tensile strength of composites [23]. On the other hand, lignin is a particle with a high modulus and it is expected that it would lend stiffness to the composite material [22]. Therefore, the tensile modulus remained approximately constant. [1].

\subsubsection{Flexural properties}

The flexural strength is a mechanical property of the material, defined as the capacity of material to withstand deformation under load [24]. As reported by Thakur et al. [1], the loading of lignin in the composites affected the overall mechanical properties of the studied system significantly. The flexural and torsion modulus increased with an increase in lignin filling, while the tensile properties decreased [1]. In this study, the flexural strength decreased with the addition of $10 \%$ lignin in the composite (Table 1 ). However, the composite with $30 \%$ lignin increased flexural strength. On the other hand, the flexural modulus remained constant. The difference in the trend of the tensile and flexural properties was not well-understood [21]. Likely, the cause may be the behavior of the material towards the stretching and bending forces [21]. The maintenance in the flexural modulus properties was attributed to the improved interfacial adhesion between lignin and plastic matrix [25]. According to Thielemans et al. [26] bending strength also increased the flexural strength with the introduction of lignin in flax fiber reinforced composites.

\subsection{Thermal analysis}

\subsubsection{Differential scanning calorimetry}

The DSC thermograms for PP-lignin blends are shown in Fig. 1. The onset temperatures are slightly lower for the blends as compared to neat PP. However, the melt temperature is higher for pure PP. Lignin had little effect on the melting behavior of the biopolymer. The introduction of lignin reduces the melt temperature from $170^{\circ} \mathrm{C}$ to $166^{\circ} \mathrm{C}$ (Fig. 1). The onset 


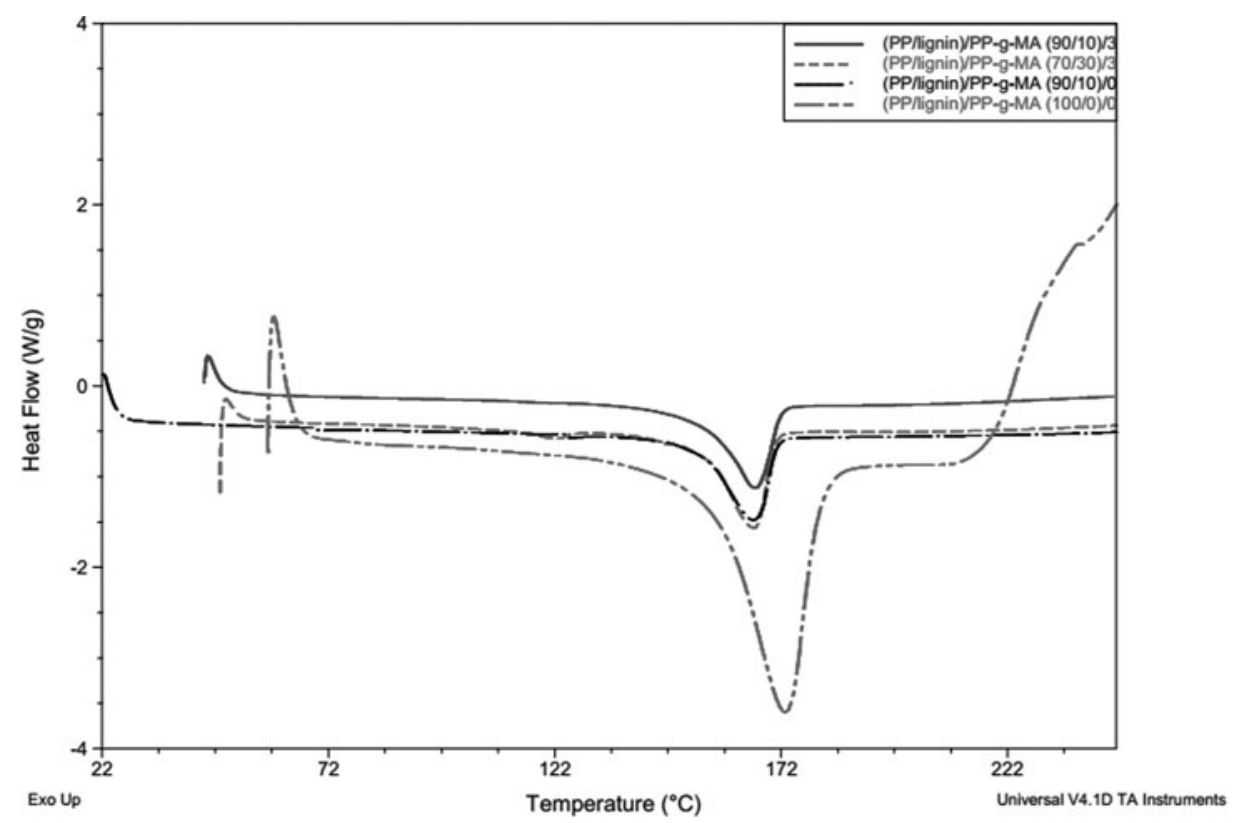

Figure 1. DSC thermograms for PP/lignin blend.

Table 2. Thermal properties of composites from DSC.

\begin{tabular}{lccc}
\hline (PP/lignin)/PP-g-MA & Melt temperature $\left({ }^{\circ} \mathrm{C}\right)$ & Onset temp $\left({ }^{\circ} \mathrm{C}\right)$ & Crystallinity $(\%)$ \\
\hline$(100 / 0) / 0$ & 172.97 & 139.26 & 88 \\
$(90 / 10) / 0$ & 165.83 & 148.39 & 35 \\
$(90 / 10) / 3$ & 166.26 & 151.11 & 38 \\
$(70 / 30) / 3$ & 166.04 & 152.47 & 37 \\
\hline
\end{tabular}

and melt temperatures along with percentage crystallinity are showed in Table 2. In our study, the degree of crystallinity decreased with filler incorporation at $10 \%$ and remains constant at $30 \%$ filler content (Table 2). The decrease in crystallinity of lignin filled composites may have been due to amorphous nature of lignin [21]. Therefore, the presence of the amorphous lignin inhibited crystallization of the PP matrix.

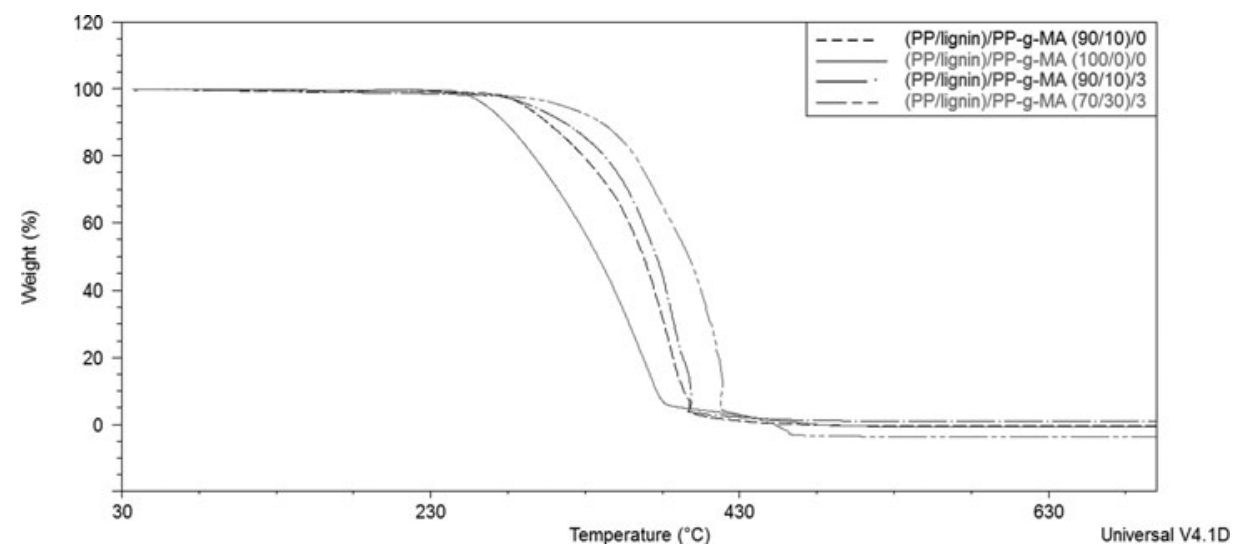

Figure 2. TGA thermogram for PP/lignin blend. 
Table 3. Thermogravimetric analysis of composites.

\begin{tabular}{lcc}
\hline (PP/lignin)/PP-g-MA & Degradation onset $\left({ }^{\circ} \mathrm{C}\right)$ & Maximum degradation temperature $\left({ }^{\circ} \mathrm{C}\right)$ \\
\hline$(100 / 0) / 0$ & 238.81 & 360.16 \\
$(90 / 10) / 0$ & 270.09 & 385.76 \\
$(90 / 10) / 3$ & 271.99 & 386.71 \\
$(70 / 30) / 3$ & 279.57 & 415.15 \\
\hline
\end{tabular}

\subsubsection{Thermogravimetric analysis}

The thermal stability was evaluated by thermogravimetric analysis as showed in Figure 2 . Degradation onset and maximum decomposition temperature of the composites increased when lignin content was increased in the composites (Table 3). In other words, the thermal stability of composites is slightly increased with lignin as filler. This can occur due to the structural characteristics of lignin which has a high density of aromatic rings, which confers greater resistance to high temperatures [27].

\section{Conclusions}

The properties of lignin-based polypropylene composites, in general, dependent on lignin concentration, as well as the addition of coupling agent to ensure better interaction between lignin and matrix. The addition of lignin produces an environmentally friendly material without loss of the desired characteristics of the virgin PP. It is clear that lignin has great potential as a filler and reinforcement for composites requiring similar properties to polypropylene.

\section{Acknowledgments}

CAPES, CNPQ, FAPESP and LWARCEL

\section{References}

[1] Thakur, V. K., Thakur, M. K., Raghavan, P., \& Kessler, M. R. (2014). ACS Sustain Chem. Eng., 2, 1072-1092.

[2] Lange, H., Decina, S., \& Crestini, C. (2013). European Polymer Journal, 49(6), 1151-1173.

[3] Duong, L. D., Luong, D. N., Binh, N. T. T., Park, I. K., Lee, S. H., Kim, D. S., Lee, Y. S., Lee, Y. K., Kim, B. W., Kim, K. H., Yoon, H. K., Yun, J.H., \& Nam, J. D. (2013). BioResources, 8, 4518-4532.

[4] Awal, A., \& Sain, M. (2013). Journal of Applies Polymer Science, 5, 2765-2771.

[5] Lora, J. H., \& Glasser, W.G. (2002). Journal of Polymers and the Environment, 10(1-2), 39-48.

[6] Gosselink, R. J., De Jong, E., Guran, B., \& Abächerli, A. (2004). Ind. Crop. Prod., 20, 121-129.

[7] Satheesh Kumar, M. N., Mohanty, A. K., Erickson, L., \& Misra, M. (2009). J. Biobased Mater. Bioeng., 3, 1-24.

[8] Setua, D. K., Sukla, M. K., Neegam, V., Singh, H., \& Mathur, G. N. (2000). Polym. Compos., 21, 988-95.

[9] Sameni, J., Krigstin, S., Rosa, D. S., Leão, A. L., \& Sain, M. (2014). Bioresources, 9, 725-737.

[10] Smook, G. A. (1992). Handbook for Pulp and Paper Technologists. Angus Wilde Publications, 2.

[11] Chakar, F. S., \& Ragauskas, A. J. (2004). Industrial Crops and Products, 2, 131-141.

[12] Morandim-Giannetti, A., Agnelli, J. A. M., Lanças, B. Z., Magnabosco, R., Casarin, S. A., \& Bettini, S. H. P. (2012). Carbohydrate Polymers, 4, 2563-2568.

[13] Zemek, J., Košíková, B., Augustín, J., \& Joniak, D. (1979). Folia. Microbiol. (Praha), 24(6), 483-486.

[14] Sena-Martins, G., Almeida-Vara, E., \& Duarte, J.C. (2008). Industrial Crops and Products, 27(2), 189-195.

[15] Stewart, D. (2008). Industrial Crops and Products, 27(2), 202-207. 
[16] Jiang, C., He, H., Yao, X., Yu, P., Zhou, L., \& Jia, D. (2015). Journal of Applied Polymer Science, 23 (132), 42044-42054.

[17] Hu, L., Stevanovic, T., \& Rodrigue, D. (2014). Journal of Applied Polymer Science, 131 (21), 4104041049.

[18] Abacherli, A., \& Doppenberg, F. US Patent 6,239,198.

[19] Scheirs, J. (2009). A Guide to Polymeric Geomembranes: A Practical Approach. John Wiley \& Sons Ltd., West Sussex, UK, 596.

[20] Sailaja, R. R. N. \& Deepthi, M. V. (2010). Materials and Design, 31(9), 4369-4379.

[21] Sahoo, S., Misra, M., \& Mohanty, A. K. (2011). Composites Part A: Applied Science and Manufacturing, 42(11), 1710-1718.

[22] Toriz, G., Denes, F., \& Young, R. A. (2002). Polymer Composites, 23(5), 806-811.

[23] Sánchez, C. G., \& Alvarez, L. A. E. (1999). Die Angew Makromol Chem., 272, 65-70.

[24] Wang, L., Perlatti D’Alpino, P. H., Lopes, L. G., \& Pereira, J. C. (2003). Journal of Applied Oral Science, 11(3), 1678-7757.

[25] Barzegari, M. R., Alemdar, A., Zhang, Y., \& Rodrigue, D. (2012). Polymer Composites, 33, 353-361.

[26] Thielemans, W., \& Wool, R. P. (2005). Polymer Composites, 26(5), 695-705.

[27] Rosas, J. M., Berenger, R., Valero-Romero, J. M., Rodriguez-Mirasol, J., \& Cordero, T. (2014). Frontiers Mater, 1(29), 1-17. 